\title{
Analisa Reward dan Kinerja Karyawan: Service Quality Sebagai Variable Moderating Pada Bank Central Asia
}

\author{
Hani Siti Hanifah ${ }^{\text {; }}$ Eliya Fatma Harahap ${ }^{2}$; \\ Fakultas Ekonomi Universitas Garut \\ hanisiti1965@uniga.ac.id
}

\begin{abstract}
Bank Central Asia (BCA) growth rate in terms of profit reached Rp 20 trillion, grew 15.8 percent (year-on-year/yoy), credit portfolio loans grew 5.3 percent to Rp 595.1 trillion, Third Party Funds (DPK) increased 1.3 percent to Rp 761.6 trillion, Operating Income grew 10.3 percent to Rp 37.8 trillion, capital adequacy ratio (CAR) was at 22.9 percent and return on assets (ROA) was 3.1 percent and return on equity (ROE) was 15.6 percent. The purpose of this study was to analyze the relationship of reward and employee performance with employee loyalty as moderating variables. The method is carried out using descriptive qualitative method with research object of Bank Central Asia. The results showed that one of the elements that influence the success in improving quality services is the existence of good human resource management that can be measured through performance, personality and psychological contracts.
\end{abstract}

Keywords: Employee Performance, Reward, Service Quality, Growth of Bank Central Asia.

\begin{abstract}
Abstrak-Tingkat pertumbuhan Bank Central Asia ( BCA ) dari aspek dilihat dari laba yang mencapai Rp 20 triliun, tumbuh 15,8 persen (year-on-year/yoy), Kredit Portofolio kredit tumbuh 5,3 persen menjadi Rp 595,1 triliun, Dana Pihak Ketiga (DPK) meningkat 1,3 persen menjadi Rp 761,6 triliun, Pendapatan Operasional tumbuh 10,3 persen menjadi Rp 37,8 triliun, Rasio kecukupan modal (CAR) berada di level 22,9 persen serta rasio pengembalian terhadap aset (ROA) 3,1 persen dan pengembalian terhadap ekuitas (ROE) 15,6 persen. Tujuan penelitian ini adalah untuk menganalisis hubungan reward dan kinerja karyawan dengan employee loyalty sebagai variabel moderating. Metode yang dilakukan dengan menggunakan metode deskriptif kualitatif dengan objek penelitian Bank Central Asia. Hasil penelitian menunjukkan salah satu unsur yang berpengaruh terhadap keberhasilan dalam meningkatkan pelayanan yang berkualitas adalah adanya manajemen sumber daya manusia yang baik yang dapat diukur melalui kinerja, kepribadian dan kontrak psikologis.
\end{abstract}

Kata Kunci : Kinerja Karyawan, Reward, Service Quality, Pertumbuhan Bank Central Asia.

\section{PENDAHULUAN}

Bank Central Asia ( BCA ) Tbk mampu mencatatkan kinerja yang solid hingga akhir triwulan I 2020 di tengah pandemic covid-19. Pada triwulan pertama 2020, BCA dan entitas anak melaporkan laba bersih konsolidasi sebesar Rp6,6 triliun atau meningkat 8,6\% dibandingkan periode yang sama tahun sebelumnya. BCA mencatat pertumbuhan pendapatan operasional yang tinggi sebesar 17,3\% menjadi Rp19,6 triliun, didukung oleh pertumbuhan kredit dan kinerja yang solid. Posisi keuangan yang kokoh menjadi fondasi kuat bagi kami menghadapi ketidakpastian akibat pandemi COVID-19 (IDX: BBCA. https://id.tradingview.com/symbols/IDX-BBCA/2020 ). BBCA mengambil langkah besar dengan menjadi perusahaan publik. Penawaran Saham Perdana berlangsung di tahun 2000, dengan menjual saham sebesar 22,55\% yang berasal dari divestasi BPPN. Setelah Penawaran Saham Perdana itu, BPPN masih enguasai 70,30\% dari seluruh saham BCA. Penawaran saham kedua dilaksanakan di bulan Juni dan Juli 2001, dengan BPPN mendivestasikan 10\% lagi dari saham miliknya di BCA. Kebijakan ini memacu pertumbuhan BCA hingga ini dan memperkokoh tradisi tata kelola perusahaan yang baik, kepatuhan penuh pada regulasi, pengelolaan risiko secara baik dan komitmen pada nasabahnya baik sebagai bank transaksional maupun sebagai lembaga intermediasi finansial [1].

Mangkunegara (2005 ), kinerja adalah hasil dari kerja secara kualitas dan kuantitas yang sudah tercapai oleh seorang karyawan maupun pegawai pada pengembanan tugas sesuai tanggung jawab yang sudah diserahkan kepadanya. Indikator kinerja dapat dilihat dari segi kualitas dimana setiap pekerjaan yang dihasilkan oleh karyawan dinilai kualitasnya berdasarkan perbandingan dengan kemampuan kerjanya serta kesempurnaan dalam pelaksanaan tugas [2], [3]. Ukuran kinerja keuangan berdasarkan SK Men.Keu. Nomor KEP. 792/MK/IV/12/1970 tanggal 7 
Desember 1970 tentang lembaga keuangan yang telah diubah dan ditambah terakhir dengan keputusan Menteri Keuangan No. 280/KMK/10/1989 tanggal 25 Maret 1989 tentang pengawasan dan pembinaan lembaga keuangan bukan bank serta ditindak lanjuti dengan Surat Edaran Bank Indonesia No. SE. 23/21/BPPP disebutkan bahwa kinerja lembaga keuangan adalah mengenai permodalan, kualitas aktiva produktif, aspek manajemen, rentabilitas, dan likuiditas. Informasi mengenai laporan keuangan bank sebagai salah satu upaya untuk membantu para pelaku bisnis dalam menilai kondisi keuangan suatu bank.. Analisis rasio merupakan analisis yang digunakan untuk mengetahui hubungan pos-pos yang ada dalam suatu laporan keuangan atau pos-pos antara laporan keuangan, neraca dan laporan laba rugi [4]. Analisis rasio keuangan merupakan teknik analisis yang sering dipakai, karena merupakan teknik yang paling cepat untuk mengetahui kinerja keuangan bank.

Reward (Penghargaan) imbalan adalah jumlah pembayaran yang diterima dan tingkat kesesuaian antara pembayaran tersebut dengan pekerjaan yang dilakukan [5]. Sistem reward dalam bentuk kompensasi yang menjanjikan merupakan faktor yang mendorong timbulnya sikap loyalitas karyawan pada BCA. Kompensasi dari level Account Officer Team Leader dengan gaji $\mathrm{Rp}$ 16,5 juta hingga Customer Service: Rp 3,9 juta [6]. Sistem ini mampu merefleksikan dan memberikan penghargaan yang pantas atas pencapaian kerja keras karyawan. Tunjangan Hari Raya, Tunjangan Akhir Tahun, Bonus Tahunan diberikan mengacu pada kinerja dan pencapaian karyawan dalam satu tahun atau periode waktu yang ditentukan, Benefit, Kesehatan, BCA bekerjasama dengan klinik dan dokter untuk memberikan layanan kesehatan bagi karyawan, Fasilitas pinjaman untuk kepemilikan rumah dan mobil bagi karyawan dengan suku bunga yang sangat menarik. Perlakukan khusus dalam layanan perbankan di BCA, antara lain rate khusus, bebas biaya rekening, bebas biaya tahunan kartu kredit, bebas biaya transaksi, bantuan biaya pendidikan bagi karyawan yang ingin melanjutkan studi ke jenjang S1 dan S2, kesempatan mengikuti pelatihan dan pembelajaran serta rekreasi dengan unit kerja.

BCA percaya bahwa keseimbangan antara kehidupan karir dan kehidupan keluarga merupakan faktor yang sangat penting dalam menunjang produktivitas karyawan yang akan menularkannya pada kualitas pelayanan pada nasabah [7]. Service Quality (Kualitas Pelayanan) upaya pemenuhan kebutuhan dan keinginan konsumen serta ketepatan penyampaiannya dalam mengimbangi harapan konsumen [8]. Kualitas pada pelayanan ini jadi begitu penting karena akan berdampak langsung terhadap citra perusahaan serta keuntungan bagi perusahaan. Suatu perusahaan dianggap sudah mendapat nilai baik dari konsumen, maka konsumen tersebut akan memberikan timbal balik yang baik, dan kemungkinan besar konsumen akan menjadi pelanggan tetap atau repeat buyer. Pelayanan pada nasabah antara lain dalam berbagai produk BCA, diantaranya Produk Simpanan, Kartu Kredit, Fasilitas Kredit, Layanan Transaksi Perbankan, Layanan Cash Management, Produk Bancassurance, Standby LC/Bank Garansi, Pembiayaan Eksport Import (Trade Finance), Fasilitas Valuta Asing, Perbankan Elektronik, Surat Kredit Berdokumen Dalam Negeri (SKBDN Local LC), Produk Investasi Reksa Dana, dan Produk Investasi Obligasi harus mampu terjual secara optimal yang akan melahirkan kinerja secara simultan dalam suatu perusahaan dimana kualitas pelayanan karyawan dalam melayani semua produk BCA tersebut memiliki peran yang dominan bagi tercapainya outcome yang diharapkan. Pada tahun 2016 BCA memperoleh beberapa penghargaan sebagai bentuk pengakuan atas komitmen Bank dalam menyediakan lingkungan kerja yang produktif. Penghargaan tersebut yaitu Indonesia Human Capital Award - kategori Best Employee Engagement dari Majalah Economic Review; Indonesia Best Companies in Creating Leaders from Within sebagai Platinum Champion dari majalah SWA dan NBO consulting group; dan Stellar Workplace Award untuk kategori Large Size Employer dari harian Kontan dan GML Performance Consulting.

\section{KAJIAN PUSTAKA}

\subsection{Reward}

Reward atau penghargaan adalah semua pendapatan yang berbentuk uang, barang langsung atau tidak langsung yang diterima karyawan sebagai imbalan atau jasa yang diberikan kepada perusahan [9].

\subsection{Service Quality ( Kualitas Pelayanan )}

Kualitas pelayanan menjelaskan perbandingan di antara tingkat layanan yang disampaikan perusahaan dibandingkan ekspektasi pelanggan [10]. Kualitas layanan diwujudkan melalui pemenuhan kebutuhan dan keinginan pelanggan serta ketepatan penyampaiannya dalam mengimbangi atau melampaui 
harapan pelanggan [11]. Reward diibaratkan pertukaran, konsep pertukaran (exchange) ini terjadi manakala individu merasa berkewajiban untuk membalas terhadap yang lainnya apabila diyakini telah memberikan kontribusi kepada salah satu pihak [12].

\subsection{Kinerja Karyawan}

Performance atau kinerja adalah hasil kerja yang dapat dicapai oleh seseorang atau kelompok orang dalam suatu perusahaan sesuai dengan wewenang dan tanggung jawab masing-masing dalam upaya pencapaian tujuan perusahaan secara ilegal, tidak melanggar hukum dan tidak bertentangan dengan moral dan etika (Rivai dan Basri, 2004; Harsuko 2011). Sementara itu (Riani, 2011) performansi mencakup sikap (attitude), kemampuan (ability) dan prestasi.

Rangkaian penelitian ini dapat di gambarkan dalam model penelitian di bawah ini :

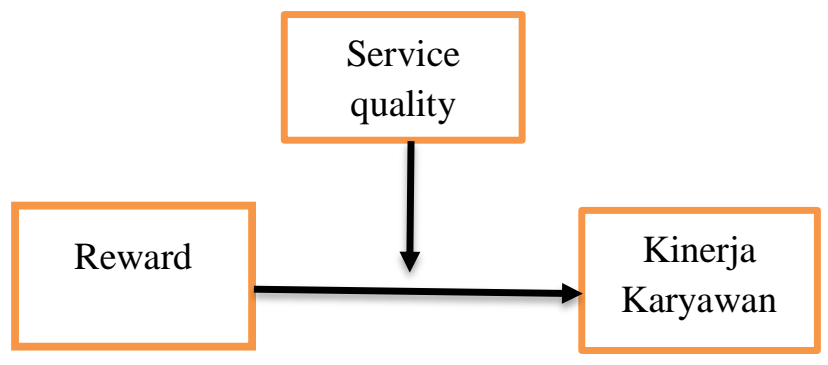

Gambar 2. Model Penelitian

\section{METODE PENELITIAN}

Metode yang dilakukan dengan menggunakan metode deskriptif kualitatif pada bca. penelitian kualitatif merupakan suatu strategi inquiri yang menekankan pencarian makna, pengertian, konsep, karakteristik, gejala, simbol maupun deskripsi tentang suatu fenomena; fokus dan multimetoda, bersifat alami dan holistik; mengutamakan kualitas, menggunakan beberapa cara, serta disajikan secara naratif. dari sisi lain dan secara sederhana dapat dikatakan bahwa tujuan penelitian kualitatif adalah untuk menemukan jawaban terhadap suatu fenomena atau pertanyaan melalui aplikasi prosedur ilmiah secara sistematis dengan menggunakan pendekatan kualitatif [13]. Jenis data yang digunakan dalam penelitian ini bersifat kualitatif yang diperoleh dari data primer hasil wawancara dan pengamatan pergerakan harga saham dan data sekunder yang didapatkan secara tidak langsung, meliputi keterangan ataupun literatur yang berhubungan dalam penelitian dengan sifat melengkapi serta mendukung data primer seperti jurnal, buku, internet yang berhubungan terhadap jurnal [14].

Sugiyono (2015) mengemukakan bahwa teknik pengumpulan data merupakan langkah yang paling strategis dalam penelitian, karena tujuan utama dari penelitian adalah mendapatkan data. dalam penelitian ini pengumpulan data diperoleh melalui 2 cara, yaitu dengan penelitian pustaka dan riset internet [15]. Tahap analisis data dengan cara mereduksi data. reduksi data adalah proses penting dalam rangka memahami data secara rasional, kritis dan instrumental untuk keperluan penelitian. reduksi data diartikan sebagai proses pemilihan, pemusatan perhatian pada penyederhanaan, pengabstrakan, dan transformasi data kasar yang muncul dari catatan-catatan tertulis di lapangan. triangulasi dapat dilakukan dengan menggunakan teknik yang berbeda [16] yaitu wawancara, observasi dan dokumen. proses reduksi data dalam penelitian kuantitatif menghasilkan grafik, tabel, diagram, dan sebagainya yang menunjukkan hasil pengukuran suatu fenomena. dalam penelitian kualitatif, reduksi data menghasilkan pengelompokan narasi atau deskripsi secara tematik dalam laporan penelitian [17].

\section{HASIL DAN PEMBAHASAN}

Tabel 1. Laporan Finansial Bank Central asia Desember 2020

\begin{tabular}{llc}
\hline Nama & Perusahaan & Industri \\
\hline Rasio P/E TTM & 30,98 & 14,8 \\
\hline $\begin{array}{l}\text { Harga terhadap } \\
\text { Penjualan TTM }\end{array}$ & 10,71 & 3,92 \\
\hline $\begin{array}{l}\text { Harga terhadap Arus } \\
\text { Kas MRQ }\end{array}$ & 20,95 & 19,85 \\
\hline $\begin{array}{l}\text { Harga terhadap Arus } \\
\text { Kas Bebas TTM }\end{array}$ & 17,03 & 31,02 \\
\hline $\begin{array}{l}\text { Harga terhadap Aset } \\
\text { MRQ }\end{array}$ & 4,79 & 2,14 \\
\hline $\begin{array}{l}\text { Harga terhadap Aset } \\
\text { Tetap MRQ }\end{array}$ & 4,78 & 2,14 \\
\hline
\end{tabular}




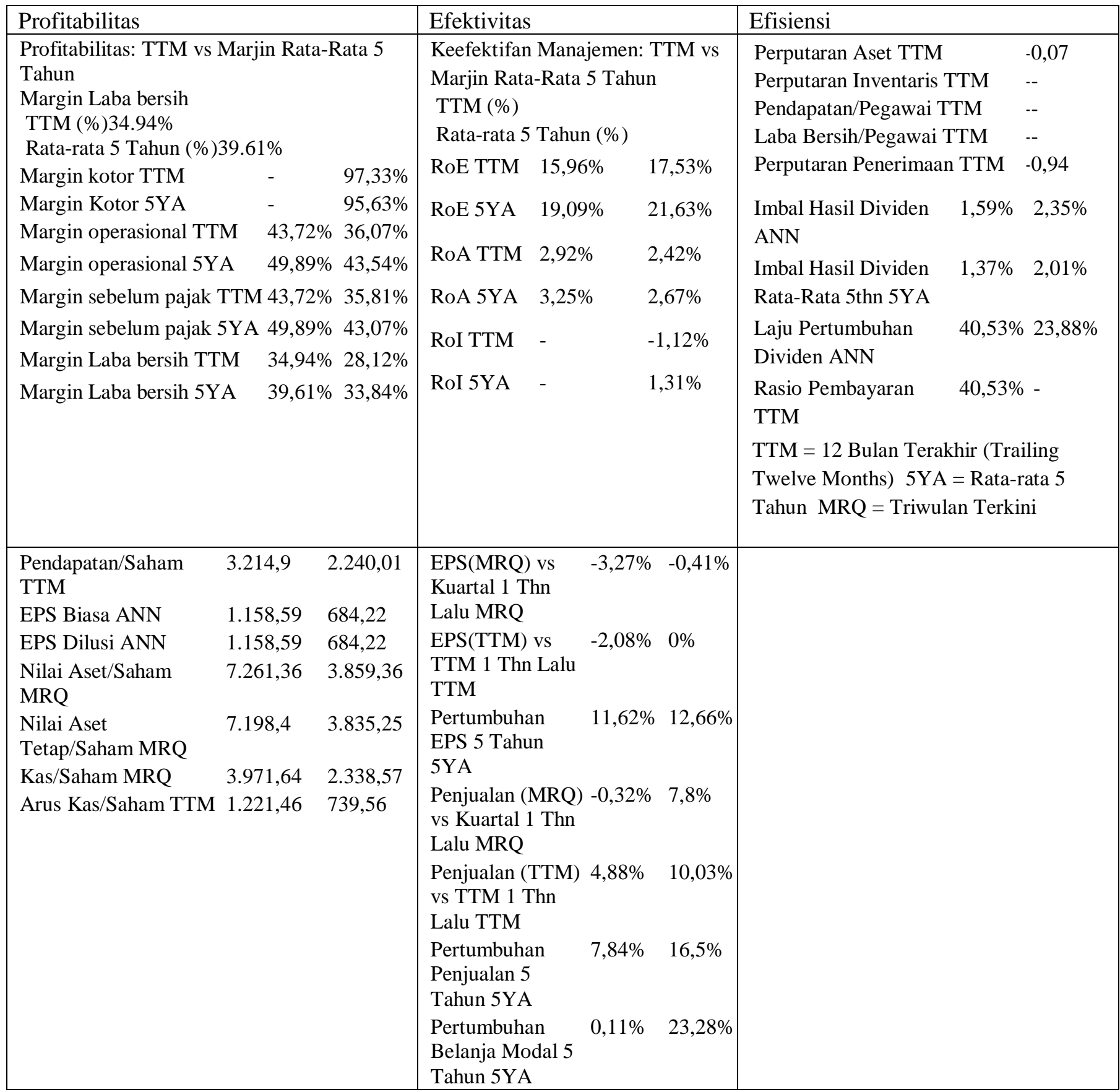

Sumber : IDX BBCA https://id.tradingview.com/symbols/IDX-BBCA/2020

Hasil analisis rasio keuangan perbankan pada analisis rasio rentabilitas, kondisi kinerja keuangan dapat dikatakan baik, rata-rata pada ROA sebesar 2,10\%, ROE sebesar 18,43\%, dan BO/PO sebesar $87,10 \%$ telah memenuhi standar Bank Indonesia [19]. Ada beberapa output dari kinerja karyawan baik level atas hingga ke bawah secara holistik di BCA (Fajar
Febrianto, 2020), diantaranya adalah laba sebelum provisi dan pajak yang mencapai $\mathrm{Rp} 21,5$

triliun, tumbuh 15,8 persen (year-on-year/yoy), Kredit Portofolio kredit tumbuh 5,3 persen menjadi Rp 595,1 triliun, Dana Pihak Ketiga (DPK) meningkat 1,3 persen menjadi Rp 761,6 triliun, Pendapatan Operasional tumbuh 10,3 persen menjadi $\mathrm{Rp} 37,8$ triliun, Rasio kecukupan modal (CAR) berada di level 
22,9 persen serta rasio pengembalian terhadap aset (ROA) 3,1 persen dan pengembalian terhadap ekuitas (ROE) 15,6 persen.

Pertumbuhan yang sehat dari Bank Central Asia. Menurut Cahyaningrum (2012) ada dua macam analisis untuk menentukan pertumbuhan laba yaitu analisis fundamental dan analisis teknikal. Hal tersebut meliputi

a. Analisis fundamental Analisis fundamental merupakan analisis yang berhubungan dengan kondisi keuangan perusahaan. Dengan analisis fundamental diharapkan calon investor akan mengetahui bagaimana operasional dari perusahaan yang nantinya akan menjadi milik investor, apakah sehat atau tidak, apakah menguntungkan atau tidak dan sebagainya. Dalam company analysis, para analis akan menganalisis laporan keuangan perusahaan yang salah satunya dengan rasio keuangan. Para analis fundamental mencoba memprediksikan pertumbuhan laba di masa yang akan datang dengan mengestimasi faktor-faktor fundamental yang mempengaruhi pertumbuhan laba yang akan datang, yaitu kondisi ekonomi dan kondisi keuangan yang tercermin melalui kinerja perusahaan. b. Analisis teknikal Analisis teknikal sering dipakai oleh investor, dan biasanya data atau catatan pasar yang digunakan berupa grafik. Analisis ini berupaya untuk memprediksi pertumbuhan laba di masa yang akan datang dengan mengamati perubahan laba di masa lalu.

Pertumbuhan bank melalui indikator diatas ditunjang oleh adanya sumber daya manusia yang mumpuni sebagai unsur utama di dalam kinerja bank. Efektivitas staff layanan merupakan unsur kritis. Implikasinya, sukses tidaknya layanan bersangkutan ditunjang oleh kemampuan organisasi dalam melakukan proses rekrutmen dan seleksi, penilaian kinerja, sistem kompensasi, pelatihan, dan pengembangan karyawannya secara efektif. Adanya plat form perusahaan terutama dalam memaksimalkan kinerja mengharuskan kejelasan job descpription dan job definition yang erat berkaitan dengan kinerja diantaranya factor reward dan kualitas pelayanan. Khusus pada BCA yakni pada sektor jasa dimana kualitas pelayanan memegang peranan penting sebagai faktor penunjang dari pertumbuhan bank itu sendiri dengan peningkatan pada jumlah nasabah. Beberapa penelitian menunjukkan pentingnya reward untuk meningkatkan kinerja yang dapat bisa berupa kenaikan gaji, penghargaan, promosi jabatan, dan pencapaian ( Riky Septiadi1, Akhmad Samhudi2, Syahrani,
Adapun service quality merupakan mediator dalam pencapaian kinerja sejalan dengan penelitian Muhammad Jazuli, Didi Samanhudi, Handoyo Handoyo( 2020 ) Kualitas pelayanan yang diberikan dimana dimensi service quality diperoleh nilai gap positif terhadap kinerja.

Suatu organisasi dalam rangka mempertahankan dan mengembangkan hidupnya, akan mengalami pasang surut sebagai salah satu bagian dari proses menuju kematangannya. Dalam proses tersebut anggota-anggota organisasi yang adalah individu-individu dalam organisasi itu sendiri pasti terlibat aktif di dalamnya. Perilaku-perilaku individu inilah yang berperan penting dalam kehidupan organisasi. Bahkan dapat dikatakan individu-individu tersebut merupakan urat nadi berkembang tidaknya organisasi. Dengan kata lain bahwa perilaku-perilaku individu dalam organisasi pasti memberi dampak pada perilaku organisasi. (Nunung Yuliastuti, 2014).

BCA memiliki komitmen untuk mengembangkan sumber daya manusia sebagai aset penting yang diperlukan dalam mendukung implementasi inisiatif strategis secara efektif sekaligus memberikan pelayanan terbaik bagi nasabah. Secara berkesinambungan BCA menyediakan program pelatihan dan pengembangan secara berkala, menanamkan budaya kerja berbasis kinerja (performance-based work culture), serta secara aktif memberikan kesempatan pengembangan karir bagi karyawan. Program-program pengembangan tersebut diimbangi dengan upaya BCA dalam membangun work-life balance untuk meningkatkan produktivitas dan efektivitas karyawan.

Dalam beberapa tahun terakhir, proses regenerasi dan suksesi kepemimpinan menjadi prioritas BCA untuk memastikan kesinambungan organisasi yang solid. BCA berkomitmen untuk menjadi perusahaan pilihan (employer of choice) para pencari kerja dan berupaya membangun lingkungan kerja yang nyaman dan kondusif. BCA juga secara konsisten mengembangkan dan memperkenalkan employee value proposition yang merupakan nilainilai khusus Bank yang mengedepankan prinsip continuous improvement dan friendly environment ( Laporan Tahunan 2016). Pada tahun 2016 BCA telah menyelenggarakan in-class training yang diikuti oleh 63.460 karyawan dalam 2.274 kelas selama 387.775 hari pelatihan. Selain itu, BCA juga mengembangkan program e-learning, suatu metode pembelajaran berbasis teknologi yang lebih fleksibel melalui penggunaan intranet. Modul-modul e-learning terus 
disempurnakan dan diperbaharui sejalan dengan perkembangan bisnis dan tren sektor perbankan. Pada tahun 2016, program e-learning tersebut telah diikuti oleh 34.307 peserta dibandingkan 19.653 peserta pada tahun 2015. Para karyawan diberikan kesempatan untuk mengikuti program pelatihan eksternal yang sesuai dengan kebutuhan spesifikasi bidangnya. BCA juga bekerja sama dengan lembaga pelatihan eksternal dalam menyediakan kursus bahasa Inggris dan Mandarin [20].

Dalam Upaya melindungi kesehatan para nasabah dan karyawan sebagai bagian dari pelayanan yang dioptimalkan oleh seluruh entitas perusahaan, BCA mengambil langkah-langkah proaktif dalam mengimplementasikan protokol kesehatan, termasuk di antaranya melakukan pemeriksaan suhu di kantor cabang, mengatur physical distancing, menerapkan kebijakan work from home bergiliran, menerapkan pembagian operasional kerja (split operation), menyediakan bus khusus karyawan, dan memfasilitasi karyawan dan pengunjung dalam melakukan penilaian mandiri atas risiko COVID-19. Bagi komunitas, Bakti BCA menyediakan dukungan sosial dan donasi, termasuk bantuan kesehatan seperti Alat pelindung Diri (APD) dan sejumlah ventilator untuk beberapa rumah sakit [21].

Pada akhir Juni 2020, BCA melayani 22,5 juta rekening nasabah dan memproses sekitar 30 juta transaksi setiap harinya didukung oleh 1.251 kantor cabang, 17.360 ATM, serta layanan internet dan mobile banking dan contact center Halo BCA yang dapat diakses 24 jam. Sebagai apresiasi atas kontribusi karyawan dan guna meningkatkan loyalitas, BCA senantiasa memperhatikan kesejahteraan karyawan dan mengelola kebijakan remunerasi yang kompetitif sesuai dengan kinerja dalam bekerja. Hal ini ditunjukkan oleh BCA dengan memberikan remunerasi yang meliputi imbalan kerja bersifat moneter berupa gaji, bonus dan tunjangan lainnya maupun imbalan kerja yang bersifat non-moneter. BCA menyediakan beberapa fasilitas kesehatan, termasuk memfasilitasi kepesertaan dalam BPJS Kesehatan guna mendukung kesehatan para karyawan dan keluarganya (PT Bank Central Asia Tbk - Laporan Tahunan 2017).

Dalam kondisi persaingan dunia bisnis termasuk sektor jasa kinerja yang optimal adalah hal yang krusial dengan berbagai strategi yang dilakukan untuk membuat konsumen atau nasabah menyimpan kepercayaannya pada perusahaan yang dimaksud secara berkelanjutan [22].

\section{KESIMPULAN DAN SARAN}

Berdasarkan hasil penelitian yang telah dilakukan, dapat disimpulkan bahwa Tingkat Pertumbuhan Bank Central Asia ( BCA ) dilihat dari laba sebelum provisi dan pajak yang mencapai $\mathrm{Rp} 20$ triliun, tumbuh 15,8 persen (year-on-year/yoy). Proses regenerasi dan suksesi kepemimpinan menjadi prioritas BCA untuk memastikan kesinambungan organisasi yang solid yang mengedepankan prinsip continuous improvement dan friendly environment. Hubungan antara reward dan kinerja dengan service quality sebagai variable intervening, salah satu unsur yang berpengaruh terhadap keberhasilan perusahaan dengan manajemen sumber daya manusia yang baik dapat diukur melalui kinerja, dimana peran reward dan quality service menjadi sangat krusial dalam sektor jasa tertentu seperti Bank Central Asia.

Adapun beberapa saran terangkum yaitu, layanan perbankan BCA yang selalu mengikuti perkembangan teknologi informasi masih perlu disempurnakan untuk mengurangi rasa ketidaknyamanan nasabah. Konsetrasi investasi yang fokus pada korporasi perusahaan menengah keatas rawan dengan kredit macet pada saat krisis ekonomi dan mata uang yang fluktuatif, kebijakan diversifikasi investasi dapat mengamankan aset perusahaan. BCA bukan pilihan utama masyarakat oleh karena itu peningkatan kinerja harus terus dilakukan agar dapat bersaing dengan sehat.

\section{REFERENSI}

[1] Anwar Prabu Mangkunegara (2005 ), Evaluasi Kinerja Sumber Daya Manusia, Penerbit Refika Aditama, Bandung

[2] IDX BBCA. https://id.tradingview.com/symbols/IDXBBCA

[3] Nasution (2003). Metode Penelitian Naturalistik Kualitatif. Bandung: Tarsito

[4] Norisa Saifuddin. BCA. 2020. https://www.idntimes.com/business/economy/i ndiana

[5] Nunung Yuliastuti, 2014. Kepribadian Dan Pengaruhnya Terhadap Perilaku Organisasi (Suatu Kajian Teoritis Terhadap Kepribadian Dalam Perilaku Organisasi). 
[6] Http://www.updkediri.ac.id/wpcontent/uploads/2014/06/Kepribadian-NPengaruhnya-Thd-Perilaku-Organisasi.Pdf

[7] PT Bank Central Asia Tbk. Laporan Tahunan 2016. https://karir.bca.co.id/keseharian-di-bca/

[8] PT Bank Central Asia Tbk - Laporan Tahunan 2017.

[9] Sandy Ayu Sartika, 3 years ago. https://www.qerja.com/journal/view/9956bekerja-di-bank-central-asia-review-dan-gajipegawai/2/

[10] Sugiyono. 2015. Metode Penelitian Pendidikan Pendekatan Kuantitatif, Kualitatif dan R\&D”. Bandung: Alfabeta 13

[11] Suwarto. 2011.Perilaku Keorganisasian : Universitas Atma Jaya Yogyakarta

[12] Rivai dan Basri (2005). Manajemen Sumber Daya Manusia untuk Perusahaan Dari Teori Ke Praktik. Jakarta: PT Raja Grafindo Persada

[13] Tjiptono. dkk, Pemasaran Strategik, Penerbit ANDI, Yogyakarta, 2008, hal. 70. 9

[14] Tjiptono, Service Management Mewujudkan Layanan Prima, Penerbit Andi, Yogyakarta, 2008, hal. 77. 4 Ibid. DOI: https://doi.org/10.31842/jurnal-inobis.v1i2.30

[15] Muhammad Jazuli, Didi Samanhudi , Handoyo. 2020. Analisis Kualitas Pelayanan Dengan Menggunakan Metode Service Quality (Servqual) Dan Importance Performance Analysis (IPA) di PT. XYZ. JUMINTEN. Vol 1 No 1. DOI: https://doi.org/10.33005/juminten.v1i1.16

[16] Sugiyono. 2005. Metode Penelitian Administrasi. Bandung: Alfabeta IDX BBCA
https://id.tradingview.com/symbols/IDX$\mathrm{BBCA} / 2020$

[17] A.Muri Yusuf. 2014. Metodologi Penelitian Kuantitatif, Kualitatif \& Penelitan Gabungan. Jakarta: Prenadamedia Group

[18] Cahyaningrum, Ndaru Hesti, 2012, Analisis Rasio Keuangan dalam Memprediksi Pertumbuhan Laba (Studi Kasus : Perusahaan Manufaktur yang Terdaftar di Bursa Efek Indonesia Periode 2005 sampai dengan 2010), Semarang : Fakultas Ekonomika dan Bisinis Universitas Diponegoro. Volume II No. 1, Februari 2017 ISSN 2502 - 3764 Jurnal Penelitian Ekonomi dan Akuntansi 333

[19] Ruswaji. Analisis Rasio Keuangan Perbankan Sebagai Alat Ukur Kinerja Keuangan Bank (Studi Kasus PD. BPR Bank Daerah Lamongan Periode 2012 -2016) Volume II No. 1, Februari 2017 ISSN 2502 - 3764 Jurnal Penelitian Ekonomi dan Akuntansi 333

[20] Kasmir . 2010. Manajemen Perbankan. Jakarta: Rajawali Press. Analisis Sistem Reward Dan Punisment Terhadap Kinerja Karyawan Pata PT. Daya Anugrah Mandiri Divisi Service Banjabaru

[21] Riky Septiadi, Akhmad Samhudi, Syahrani. Fakultas Ekonomi Program Studi Manajemen Universitas Islam Kalimantan Muhammad Arsyad Al Banjari. http://eprints.uniskabjm.ac.id/1665/1/Jurnal\%20Riky.pdf

[22] Hasibuan, Malayu SP. (2007). Manajemen Sumber Daya Manusia. Jakarta : Bumi Aksara 